\title{
Comparative Proteomic Analysis of Erythropoiesis Tissue Head Kidney Among three Antarctic Fish Species
}

Ruonan Jia

Shanghai Ocean University

Shaojun Huang

Shanghai Ocean University

Wanying Zhai

Shanghai Ocean University

Shouwen Jiang

Shanghai Ocean University

Wenhao Li

Shanghai Ocean University

Faxiang Wang

Shanghai Ocean University

Qianghua Xu ( $\square$ qhxu@shou.edu.cn )

Shanghai Ocean University https://orcid.org/0000-0003-0351-1765

\section{Research Article}

Keywords: Antarctic icefish, erythropoiesis, hematopoiesis, head kidney, immunity

Posted Date: June 15th, 2021

DOI: https://doi.org/10.21203/rs.3.rs-504121/v1

License: (a) (1) This work is licensed under a Creative Commons Attribution 4.0 International License. Read Full License 


\section{Abstract}

Antarctic icefish is the only known vertebrate species that lacks oxygen-carrying hemoglobin and functional erythrocytes. To reveal the unique hematopoietic process of icefish, we used an integrated approach including tandem mass tag (TMT) labeling and liquid chromatography-tandem mass spectrometry (LC-MS/MS) to quantify the dynamic changes in the head kidney whole proteome of a white-blooded icefish, Chionodraco hamatus, compared to those in two other red-blooded Antarctic fish, Trematomus bernacchii and Notothenia coriiceps. Of the 4,672 identified proteins, in the Antarctic ice fish head kidney, 123 proteins were significantly up-regulated and 95 proteins were down-regulated. The functional grouping of differentially expressed proteins based on KEGG pathway analysis shows that white blood fish and red blood fish have significant differences in erythropoiesis, heme biogenesis, leucocyte and platelet cell development. The proteins involved in the hematopoietic process in icefish showed a clear trend of downregulation of erythroid lineage marker proteins and upregulation of lymphoid and megakaryocytic lineage marker proteins, including CD9, ITGB2, and MTOR, which suggests a shift in hematopoiesis in the icefish head kidney due to the loss of erythrocytes. The results of the present study not only provide basic datasets for the head kidney proteins of Antarctic fishes, but also provide important references for studies on immunity and hematopoiesis in various species.

\section{Introduction}

The marine environment of the Antarctica is characterized by a long-term icy snow cover on the ocean, which results in the temperature of sea water being constantly maintained at $-1.9^{\circ} \mathrm{C}$ (Gonzalez-Aravena et al. 2016). Because of low temperature, more oxygen can dissolve in cold water, leading to the Southern Ocean becoming an oxygen-rich water region (O'Brien et al. 2020). The modern Southern Antarctic fish fauna comprises over 300 species of fishes (Eastman 2005; Thatje et al. 2008), and among them, the suborder Notothenioids (perciform) is the most abundant endemic fish fauna, which underwent considerable diversification with significant ecological differences. This suborder is divided to six families that include Notothenioidae, Artedidraconidae, Bovichtidae, Harpagiferidae, Bathydraconidae, and Channichthyidae (Buonocore et al. 2006). To survive in such isolated and harsh cold conditions, these fishes have evolved numerous unique specializations to adapt, particularly antifreeze glycoproteins, which prevent freezing of the body fluids of the fish (Chen et al. 1997). The icefish of the Channichthyidae family, also known as the "white-blooded" fish, are the only species that have developed in this region due to the to lack of hemoglobin and functional active erythrocytes (Ito et al. 1995).

The Antarctic icefish Chionodraco hamatus (Perciformes: Channichthyidae) is a benthic fish that lives in the subzero waters of the Antarctic Ocean (Chen et al. 2019; Gerdol et al. 2019). As the only known vertebrate group that lacks hemoglobin (Evans et al. 2021), the blood circulation system of icefish has undergone large compensatory physiological changes. Trematomus bernacchii (Perciformes: Nototheniidae) (Della Pelle et al. 2020) and Notothenia coriiceps (Perciformes: Nototheniidae) (Cao et al. 2016), two red-blooded notothenioid fishes, share a similar living environment with Chionodraco hamatus $(\mathrm{CH})$. The hematopoietic system, especially the immune system of the Antarctic fishes (the 
icefish in particular), has undergone a rigorous selection process due to the harsh long-term coldness (Romano et al. 2000).

Head kidney is the main hemopoietic tissue in fish and is also an important immune organ with a cellular composition of erythrocytes and leucocytes, such as macrophages, granulocytes, and B lymphocytes (Romano 1998). In our previous study, we found more than 100 kinds of microRNAs, including miR-152, with high expression in the head kidney of $\mathrm{CH}$, which might ultimately result in the suppression of erythropoiesis in icefish (Chan et al.). The Antarctic fishes also serve as a good candidate to study the evolution of the immune system under extreme cold environments.

Previous studies have shown differences in the histological structure of lymphomyeloid organs of the Antarctic fish $\mathrm{CH}$ and Trematomus bernacchii (Romano et al. 2000). The transcriptome and microRNA analysis of the primary hematopoietic tissue (head kidney) of $\mathrm{CH}$ and two red-blooded revealed the evodevo mechanisms involving erythropoietic suppression through the upregulation of TGF- $\beta$ signaling (Xu et al. 2015). Unique evolution of hepcidin genes was also noted in icefish as compared to that in other Antarctic fishes. However, little is known about the proteomic profile of the primary hematopoietic and immune-related tissue (head kidney) of icefish and other Antarctic fishes. In the current study, we used an integrated method including TMT labeling and LC-MS/MS to quantify the dynamic variations in the entire proteome (Chionodraco hamatus) of head kidney of icefish $(\mathrm{CH})$ and two red-blooded notothenioids Trematomus bernacchii (TB)and Notothenia coriiceps (NC)with an aim to analyze the proteomic differences between the three Antarctic fishes. The results of the present study not only provide important references for further exploration of the unique hematopoietic process of the white-blooded icefish, but also shed a light on the innate and adaptive immune mechanisms of the Antarctic teleost.

\section{Materials And Methods}

\subsection{Sample preparation}

Chionodraco hamatus and Trematomus bernacchii individuals were gathered locally from Prydz Bay

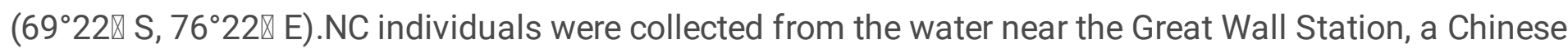
Antarctic research base $\left(62^{\circ} 12 \rrbracket S, 58^{\circ} 57 \rrbracket W\right)$ located on the Fieldes Peninsula on King George Island. Head kidney tissues were dissected from adult male fish samples and used for total protein extraction. For each species, head kidney tissues from three different adult male fish individuals were dissected and used for total protein extraction. The average body length was approximately $22 \mathrm{~cm} \mathrm{for} \mathrm{CH}$ and $\mathrm{NC}$ and approximately $15 \mathrm{~cm}$ for TB individuals.

\subsection{Protein extracts}

The head kidney tissue was ground in liquid nitrogen for 20 minutes and sonicated three times on ice with a high intensity ultrasound processor. Then the samples in triplicate for each group were solubilized and centrifuged at a low-speed instantaneously, and the supernatant and intermediate layer are taken to add cocktail (ThermoFisher Scientific, USA) and 4\% SDS(Shanghai Chinese Medicine, China).The 
suspensions were disrupted by sonication on ice for $3 \mathrm{~min}$, lysates were incubated on ice for $30 \mathrm{~min}$. Subsequently, lysates were separated by centrifuge at $4^{\circ} \mathrm{C}$ for 20 minute and collected supernatants. Protein concentration of each sample was quantified by 2-D Quant kit.

Digested trypsin for digestion, take $100 \mu \mathrm{g}$ protein and replenish the volume to $100 \mu$ with lysate, add a final concentration of $10 \mathrm{mM}$ DTT (ThermoFisher Scientific, USA) at $37^{\circ} \mathrm{C}$ for $60 \mathrm{~min}$, then adding iodoacetamide with an ultimate density of $20 \mathrm{mM}$ (Sigma) at $20^{\circ} \mathrm{C}$ for $45 \mathrm{~min}$ in the dark. Afterwards $200 \mathrm{mM}$ TEAB was added to each sample for achieve urea density of less than $2 \mathrm{M}$ (Wang et al., 2019). then centrifuged $10,000 \mathrm{~g}$ for $20 \mathrm{~min}$ and collected the precipitation. Solubilized precipitation digested overnight at $37^{\circ} \mathrm{C}$ using trypsin with the mass ratio of Trypsin to protein 1:50.

\subsection{TMT labeling}

Finally, the peptides were dried by vacuum pump, labeling TMT reagents was added in advance (Thermo Fisher Scientific, Torrance, CA, USA) per $100 \mu \mathrm{g}$ peptides, incubated for 2 hours at room temperature. Sample labeling was performed as follows: group CH: 129, group TB: 130, group NC: 131 . Add 50ul of ultrapure water and leave it at room temperature for $30 \mathrm{~min}$. Each group labeled samples of the peptide were mixtured and dried down in a vacuum, the mixtures sample containing high-performance liquid chromatography (HPLC) were separated on loaded onto UltraPerformance LC (Waters, USA) containing a C18 column in front of a 2.1x $150 \mathrm{~mm}$ X Bridge BEH300 (Waters, USA), The HPLC gradient was buffer B $(100 \% \mathrm{ACN}$ ) in buffer $\mathrm{A}$ (ammonia water, formic acid adjusted $\mathrm{pH}$ to 10 ) started with $0 \% \mathrm{~B}$ and increased to $100 \%$ B then followed by $0 \%$ B $6 \mathrm{~min}$ at a flow rate of $400 \mu \mathrm{l} / \mathrm{min}$ total over $80 \mathrm{~min}$. Collect 80 fractions based on peak shape and time and combine them into 18 fractions using rotation vacuum concentrators, the samples then were dissolved in mass spectrometry loading buffer the following analysis.

\subsection{LC-MS/MS analysis and database search}

The peptides were dissolved in $0.1 \% \mathrm{FA}$ and separated from the high-performance liquid chromatography (HPLC) analysis were combined with liquid chromatography and tandem mass spectrometry( LC-MS/MS) containing EASY-nLC 1200, Q-Exactive(Thermo, USA)and C18 column $(75 \mu \mathrm{m} \times 25 \mathrm{~cm}$, Thermo ,USA). The schemes of gradient elution rise from $4-22 \%$ solvent B $(0.1 \% \mathrm{FA}$ in $98 \% \mathrm{ACN})$ in $26 \mathrm{~min}, 22-35 \%$ in $8 \mathrm{~min}$, increased to $80 \%$ in $3 \mathrm{~min}$, and then held at $80 \%$ for the last $3 \mathrm{~min}$.

The MS data using data-dependent acquisition (DDA) model detection top 20, and following a MS measure scan over $350-1800 \mathrm{~m} / \mathrm{z}$ at a resolution of 70,000 with the fragmentation pattern of high energy collisional dissociation, and, thena full scan at a resolution of 17,500 for MS/MS measured value was conducted and the dynamic exclusion time was 30 s.

Use the PD search engine to process the MS/MS data. The Dissostichus mawsoni(DM) protein database was used as the common reference protein for set Tandem mass spectra searching (Chen et al. 2019) to study the differential protein expression patterns for the three notothenioids. In this study, DM is a closely related species of Antarctic fish. The laboratory sequenced and released the genome of DM(Chen et al. 2019). 


\subsection{Bioinformatics Methods}

Gene Ontology (GO) annotation of the proteome was derived from DM Protein Database (Chen et al. 2019). Firstly, the KEGG database description of protein is annotated by Kaas. Then use the KEGG online service tool KEGG mapper to map the comment results on the KEGG path database.

Each class of proteins was enriched by domain analysis, and the InterPro database was studied. The twotailed Fisher's exact test was used to detect the enrichment degree of differentially expressed proteins for all identified proteins (Ma et al. 2020). GO annotation divides proteins into three categories: cellular compartment, molecular function and biological process. The corrected p-value of $<0.05$ was considered to be significant.

\section{Results}

\subsection{Quantitative overview}

Reproducibility analysis of three biological replicate experiments was conducted by Pearson's correlation coefficient. For each replicate, relative expression of the proteins of $\mathrm{CH}, \mathrm{TB}$ and $\mathrm{NC}$ was determined with Pearson's correlation coefficient (Fig. 1A). 4822 proteins were identified, among which 4672 proteins were quantified. A comparison of the proteome profile of $\mathrm{CH}$ with those of TB and NC showed that 123 proteins were upregulated (quantitative ratio of $>1.2$ was considered as upregulation, $\mathrm{CH}$ vs. combined) and 95 proteins were downregulated (quantitative ratio of $<1 / 1.2$ was considered as downregulation, $\mathrm{CH}$ vs. combined) in $\mathrm{CH}$. The amount of the DEPs is summarized in Fig. $1 \mathrm{~B}$.

\subsection{Functional classification of DEPs}

The 218 DEPs were classified into three categories, namely biological processes, cellular components, and molecular functions, according to $\mathrm{GO}$ analysis $(p<0.05)$ (Fig. 2$)$. These proteins were mainly clustered into $20 \mathrm{GO}$ functional categories, which accounted for nine biological processes, nine cellular components, and two molecular functions (Fig. 2A-C). The most prevalent biological processes were response to inorganic substances, response to metal ions, erythrocyte homeostasis, and myeloid cell homeostasis, which accounted for 55\% (Fig. 2A). According to cellular component annotation, the majority of the dysregulated proteins originated from the membrane $(29 \%)$ and membrane part (15\%). Other significant components included the endomembrane system (13\%) and the endoplasmic reticulum part (9\%) (Fig. 2B). The common molecular functions included gated channel activity and ion-gated channel activity (Fig. 2C).

\subsection{G0 enrichment of differentially quantified proteins}

Figure 3 shows the results of the GO enrichment analysis. The differentially quantified proteins of the upregulated pathways for the three Antarctic fish species are shown in Fig. 3A. The most significantly 
enriched cellular components were the endoplasmic reticulum membrane, the endoplasmic reticulum membrane network, and the endomembrane system. The main molecular functions were gated channel activity, ion-gated channel activity, and ion channel activity. The biological processes were mainly enriched in the glycoprotein metabolic process, gated channel activity, and divalent metal ion transport. The differentially quantified proteins of the downregulated pathways for the three Antarctic fish species are shown in Fig. 3B. The most significantly enriched cellular components were the main axon, muscle thin filament tropomyosin, and mitotic spindle. The main molecular functions were peptide binding and amide binding. The biological processes were mainly enriched in embryonic hemopoiesis, cardiac muscle contraction, hemoglobin biosynthetic process, and hemoglobin metabolic process. The GO enrichment analysis showed that the DEPs mainly participated in membrane, binding, and metabolic processes.

\subsection{Pathway enrichment analysis of DEPs}

KEGG analysis was performed to investigate the enriched pathways for the upregulated and downregulated proteins. The upregulated proteins were mainly mapped to 10 signaling pathways, which included hematopoietic cell lineage, malaria, cell adhesion molecules, protein processing in endoplasmic reticulum, HTLV-I infection, viral myocarditis, and others (Fig. 4). There are significant differences in erythropoiesis, heme biogenesis, and leucocyte and platelet cell development between the white- and redblooded fishes (Souza et al. 2018). The downregulated proteins were mainly mapped to five signaling pathways: pentose phosphate pathway, porphyrin and chlorophyll metabolism, prion diseases, focal adhesion, and amoebiasis (Fig. 4).

On the basis of the differential protein function determined from the KEGG pathway, white-blooded fish and red-blooded fish showed significant differences in erythropoiesis and platelet cell development. The protein expression pattern of the hematopoietic process of teleosts shows that in icefish head kidney, erythropoiesis-related proteins are downregulated or almost inhibited and the production of megakaryocytic- and lymphopoiesis-related proteins is upregulated. The expression of B lymphocyte production-related proteins CD9 and ITGB2 was significantly upregulated $(p<0.05)$; the platelet production-related protein $C D 9$ was significantly upregulated, and the expression of the myeloblast production-related proteins ITGB2, CD9, and MTOR was also significantly upregulated. This was in contrast to erythropoiesis-related proteins $\beta$-Spectrin, tfr1a, and hemoglobin, which were significantly downregulated and almost showed no expression (Fig. 5). 
Table 1

Related DEPs data of haematopoietic genetic programs in the Antarctic icefish. (DEPs, Ratio $>1.2$ or Ratio $<1 / 1.2$, and a $P$ value $<0.05$ )

\begin{tabular}{|c|c|c|c|c|c|c|}
\hline Accession & $\begin{array}{l}\text { Gene } \\
\text { symbol }\end{array}$ & $\begin{array}{l}\text { Protein } \\
\text { description }\end{array}$ & $\begin{array}{l}\text { CHvsTB } \\
\text { P value }\end{array}$ & $\begin{array}{l}\text { CHvsTB } \\
\text { Ratio }\end{array}$ & $\begin{array}{l}\text { CHvsNC } \\
\text { P value }\end{array}$ & $\begin{array}{l}\text { CHvsNC } \\
\text { Ratio }\end{array}$ \\
\hline XP_020462274.1 & itgb2 & $\begin{array}{l}\text { integrin beta-2- } \\
\text { like [Monopterus } \\
\text { albus] }\end{array}$ & 0.003890 & 1.658 & 0.006600 & 2.490 \\
\hline XP_020491589.1 & mtor & $\begin{array}{l}\text { serine/threonine- } \\
\text { protein kinase } \\
\text { mTOR isoform } \\
\text { X2 [Labrus } \\
\text { bergylta] }\end{array}$ & 0.044512 & 1.257 & 0.007816 & 1.430 \\
\hline XP_008289870.1 & CD9 & $\begin{array}{l}\text { CD9 antigen-like } \\
\text { isoform X1 } \\
\text { [Stegastes } \\
\text { partitus] }\end{array}$ & 0.032751 & 9.749 & 0.002481 & 9.650 \\
\hline XP_019127726.1 & $\beta$-Spectrin & $\begin{array}{l}\text { spectrin alpha } \\
\text { chain, non- } \\
\text { erythrocytic } 1 \\
\text { isoform X3 } \\
\text { [Larimichthys } \\
\text { crocea] }\end{array}$ & 0.014578 & 0.599 & 0.027732 & 0.792 \\
\hline XP_010773129.1 & tfr1a & $\begin{array}{l}\text { transferrin } \\
\text { receptor protein } \\
1 \text { [Notothenia } \\
\text { coriiceps] }\end{array}$ & 0.016209 & 0.365 & 0.028630 & 0.454 \\
\hline COHJT7.1 & hemoglobin & $\begin{array}{l}\text { Hemoglobin } \\
\text { subunit beta-2 } \\
\text { [Dissostichus } \\
\text { eleginoides] }\end{array}$ & 0.009804 & 0.228 & 0.001228 & 0.307 \\
\hline
\end{tabular}

\section{Discussion}

In the present study, we conducted interspecies comparisons of head kidney proteomes between one icefish (CH) and two red-blooded notothenioids (TB and NC) by using TMT labeling and LC-MS/MS. We compared the expression profiles and described the differences of 123 upregulated proteins and 95 downregulated proteins. The comparison of the expression patterns of the teleost head kidney proteomes showed that the expression of erythrocyte-related proteins such as $\beta$-Spectrin, tfr $1 \mathrm{a}$, and hemoglobin was significantly downregulated in icefish; however, lymphoid and megakaryocytic lineage marker proteins, including CD9 and ITGB2, were significantly upregulated. An interesting point to note is that the lymphoid and megakaryocytic lineage marker proteins were not affected by the absence of erythrocytes and they were even upregulated in the icefish head kidney (Table 1). It is known that CD9 and ITGB2 play important roles in the development of B cells (Wang et al. 2020; Yang et al. 2020), and B lymphocytes are a subgroup of white blood cells that can differentiate into antibody-secreting cells. CD9 promotes the 
recruitment of CD10 (a protease involved in the maturation and migration of B cells (Wang et al. 2020)) in exosomes (Navarro-Hernandez et al. 2020). CD9 is not expressed in primitive or memory B cells in mammals, but is expressed in plasma cell lines (Yoon et al. 2013) and in "innate-like" B lymphocytes (Won and Kearney 2002).

CD9 has also been found in multiple aquatic species, including rainbow trout and Atlantic salmon (Fujiki et al. 2002), red stingray (Zhu et al. 2006), shrimp (Wang et al. 2010), and lamprey (Wu et al. 2012). The fact that CD9 is constitutively expressed in trout primitive $B$ cells indicates that a high proportion of primitive fish B cells is the equivalent of mammalian innate B cells (Zhu et al. 2014). ITGB2 is also an important immune effector that plays a vital role in protecting fish from a variety of pathogens (Wang et al. 2020). CD9 also plays an important role in platelet generation (Kaprielian et al. 1995; Aurora et al. 2018). Consistent with our results, Consistent with our results, Xu et al. (2015) has been reported that genes related to erythropoiesis and heme biogenesis are downregulated in the kidney of ice fish. While genes related to leukocyte differentiation and development, platelet activation, aggregation, and formation are upregulated (Xu et al., 2015). The proteomics analysis of the total protein in the head kidney of three Antarctic fish further confirmed that this general expression trend may cause a severe reduction in red blood cell differentiation of $\mathrm{CH}$, while $\mathrm{B}$ cells and platelet cells are relatively up-regulated.

The major function of erythrocytes is not only to deliver oxygen to the organs, but they are also involved in innate immune responses, as they can capture specific immune complexes such as certain pathogens and bacteria, partly through membrane electrostatic attraction, and then kill them in the liver and spleen by presenting the pathogens to Kupffer cells and antigen-presenting cells (APCs)(Ukidve et al. 2020). In our study, the number of erythrocytes in the icefish was found to be severe reduced probably due to changes in the immune response; however, at present, we are unsure whether this change is more harmful or more beneficial. A comparison of the mucus microbial communities between white-blooded $\mathrm{CH}$ and red-blooded TB individuals sampled from the same locations showed much higher levels of bacterial species diversity in the $\mathrm{CH}$ mucus samples (data not published). To our knowledge, the fish skin mucus is a viscoelastic, adhesive gel that covers the exposed skin. The skin and mucus layer of fish are regarded as the first line of defense and play an important role in preventing the entry of pathogenic bacteria and similar harmful substances (Guellec et al. 2003; Laura et al. 2012). The low temperature of the surrounding environment, however, results in inhibition of the inflammatory responses (Finn and Nielsen 2010),including phagocytosis and acquired immune responses. Therefore, it remains unclear whether the increase in the number of mucus microorganisms indicates the increased susceptibility of the $\mathrm{CH}$ immune system to attack by microorganisms or whether it represents the ways through which the fish improves its acquired immunity; further studies are needed to confirm this aspect.

The present study mainly discusses the DEPs from total proteins of head kidney of three Antarctic fish species by comparing the significant differentially expressed proteins of red-blooded TB and NC and white-blooded $\mathrm{CH}$. This study found 218 DEPs that could be used for further analysis of their related genes to provide a basis for further studies on the occurrence of red blood cells in icefish. Because there are almost no red blood cells in the Antarctic icefish, we found that among the three fish species, the 
expression of proteins is important role in B-cell production and platelet cell development in the hematopoietic cell lineage was significantly upregulated $\mathrm{CH}$. The results of this study can serve as good references for further research and exploration of the immunity and hematopoiesis of the Antarctic icefish.

\section{Declarations}

\section{Acknowledgements}

This work was supported in part by the Funding Project of the National Key Research and Development Program of China (2018YFC0310600), the Natural Science Foundation of China (No. 41761134050, 31572598,31772826 ) and the Major Science Innovation Grant from the Shanghai Education Committee (2017-01-07-00-10-E00060). Experimental protocols involving live animals were approved by the Ethics Committee for the Use of Animal Subjects of Shanghai Ocean University. The authors declare that they have no conflict of interest.

\section{Funding}

This work was supported in part by the Funding Project of the National Key Research and Development Program of China (2018YFC0310600), the Natural Science Foundation of China (No. 41761134050, 31572598,31772826 ) and the Major Science Innovation Grant from the Shanghai Education Committee (2017-01-07-00-10-E00060).

\section{Conflict of interest}

The authors declare that they have no known competing financial interests or personal relationships that could have appeared to influence the work reported in this paper.

\section{Availability of data and material}

All data generated or analysed during this study are included in this article [and its supplementary information files].

\section{Code availability}

Not applicable

\section{Authors' contributions}


QHX was responsible for the overall guidance of this article. RNJ and SJH were mainly responsible for the overall experimental process and experimental data analysis involved in this paper; WYZ and SWJ participated in sample collection and processing; WHL and FXW participated in the analysis of experimental data and image processing.

\section{Ethics approval}

Experimental protocols involving live animals were approved by the Ethics Committee for the Use of Animal Subjects of Shanghai Ocean University.

\section{Consent to participate}

Not applicable.

\section{Consent for publication}

Not applicable.

\section{References}

1. Aurora A, Wrice N, Walters TJ, Christy RJ, Natesan S (2018) A PEGylated platelet free plasma hydrogel based composite scaffold enables stable vascularization and targeted cell delivery for volumetric muscle loss. Acta Biomater 65:150-162. doi 10.1016/j.actbio.2017.11.019

2. Buonocore F, Randelli E, Paderi F, Bird S, Secombes CJ, Mazzini M, Scapigliati G (2006) The cytokine IL-1 $\beta$ from the crocodile icefish Chionodraco hamatus (Perciformes: Channichthyidae). Polar Biol 29:1018-1027. doi 10.1007/s00300-006-0145-2

3. Cao L, Huang Q, Wu Z, Cao D-D, Ma Z, Xu Q, Hu P, Fu Y, Shen Y, Chan J, Zhou C-Z, Zhai W, Chen L (2016) Neofunctionalization of zona pellucida proteins enhances freeze-prevention in the eggs of Antarctic notothenioids. Nat Commun 7 doi 10.1038/ncomms12987

4. Chan J, Hu X, Wang C, Xu Q miRNA-152 targets GATA1 to regulate erythropoiesis in Chionodraco hamatus

5. Chen L, Lu Y, Li W, Ren Y, Yu M, Jiang S, Fu Y, Wang J, Peng S, Bilyk KT, Murphy KR, Zhuang X, Hune M, Zhai W, Wang W, Xu Q, Cheng C-HC (2019) The genomic basis for colonizing the freezing Southern Ocean revealed by Antarctic toothfish and Patagonian robalo genomes. GigaScience 8 doi 10.1093/gigascience/giz016

6. Chen LB, Devries A, Cheng C (1997) Evolution of Antifreeze Glycoprotein Gene from a Trypsinogen Gene in Antarctic Notothenioid Fish. Proc Natl Acad Sci USA 94:3811-3816. doi 10.1073/pnas.94.8.3811 
7. Della Pelle G, Pera G, Belardinelli MC, Gerdol M, Felli M, Crognale S, Scapigliati G, Ceccacci F, Buonocore F, Porcelli F (2020) Trematocine, a Novel Antimicrobial Peptide from the Antarctic Fish Trematomus bernacchii: Identification and Biological Activity. Antibiotics (Basel) 9 doi 10.3390/antibiotics 9020066

8. Eastman J (2005) The nature of the diversity of Antarctic fishes. Polar Biol 28:93-107. doi 10.1007/s00300-004-0667-4

9. Evans ER, Farnoud AM, O'Brien KM, Crockett EL (2021) Thermal profiles reveal stark contrasts in properties of biological membranes from heart among Antarctic notothenioid fishes which vary in expression of hemoglobin and myoglobin. Comp Biochem Physiol B Biochem Mol Biol 252:110539. doi 10.1016/j.cbpb.2020.110539

10. Finn JP, Nielsen NO (2010) The effect of temperature variation on the inflammatory response of rainbow trout. J Pathol 105:257-268

11. Fujiki K, Gauley J, Bols N, Dixon B (2002) Cloning and characterization of cDNA clones encoding CD9 from Atlantic salmon (Salmo salar) and rainbow trout (Oncorhynchus mykiss). Immunogenetics 54:604-609. doi 10.1007/s00251-002-0506-0

12. Gerdol M, Lucente D, Buonocore F, Poerio E, Scapigliati G, Mattiucci S, Pallavicini A, Cimmaruta R (2019) Molecular and Structural Characterization of MHC Class II beta Genes Reveals High Diversity in the Cold-Adapted Icefish Chionodraco hamatus. Sci Rep 9:5523. doi 10.1038/s41598-019-42003-5

13. Gonzalez-Aravena M, Perez-Troncoso C, Urtubia R, Branco P, Paschke K (2016) Immune response of the Antarctic sea urchin Sterechinus neumayeri: cellular, molecular and physiological approach. Revista De Biologia Tropical 63:309-320

14. Guellec DL, Morvan-Dubois G, Sire JY (2003) Skin development in bony fish with particular emphasis on collagen deposition in the dermis of the zebrafish (Danio rerio). International Journal of Developmental Biology 48: págs. 217-231

15. Ito N, Komiyama NH, Fermi G (1995) Structure of Deoxyhaemoglobin of the Antarctic Fish Pagothenia bernacchii with an Analysis of the Structural Basis of the Root Effect by Comparison of the Liganded and Unliganded Haemoglobin Structures. J Mol Biol 250:648-658

16. Kaprielian Z, Cho K, Hadjiargyrou M, Patterson P (1995) CD9, a major platelet cell surface glycoprotein, is a ROCA antigen and is expressed in the nervous system. The Journal of Neuroscience 15:562-573. doi 10.1523/jneurosci.15-01-00562.1995

17. Laura M, Ensign, Craig, Schneider, Jung, Soo, Suk R, Cone (2012) Mucus Penetrating Nanoparticles: Biophysical Tool and Method of Drug and Gene Delivery. Adv Mater 24:3887-3894

18. Ma C, Wang W, Wang Y, Sun Y, Kang L, Zhang Q, Jiang Y (2020) TMT-labeled quantitative proteomic analyses on the longissimus dorsi to identify the proteins underlying intramuscular fat content in pigs. J Proteomics 213:103630. doi 10.1016/j.jprot.2019.103630

19. Navarro-Hernandez IC, Lopez-Ortega O, Acevedo-Ochoa E, Cervantes-Diaz R, Romero-Ramirez S, SosaHernandez VA, Meza-Sanchez DE, Juarez-Vega G, Perez-Martinez CA, Chavez-Munguia B, GalvanHernandez A, Antillon A, Ortega-Blake I, Santos-Argumedo L, Hernandez-Hernandez JM, Maravillas- 
Montero JL (2020) Tetraspanin 33 (TSPAN33) regulates endocytosis and migration of human B lymphocytes by affecting the tension of the plasma membrane. FEBS J. doi 10.1111/febs.15216

20. O'Brien KM, Rix AS, Grove TJ, Sarrimanolis J, Brooking A, Roberts M, Crockett EL (2020)

Characterization of the hypoxia-inducible factor-1 pathway in hearts of Antarctic notothenioid fishes. Comp Biochem Physiol B Biochem Mol Biol 250:110505. doi 10.1016/j.cbpb.2020.110505

21. Romano N (1998) Ontogeny of the immune system of fish using specific markers. S.I

22. Romano N, Ceccariglia S, Abelli L, Mazzini M, Mastrolia L (2000) Lymphomyeloid organs of the Antarctic fish Trematomus nicolai and Chionodraco hamatus (Teleostei: Notothenioidea): a comparative histological study. Polar Biol 23:321-328. doi 10.1007/s003000050451

23. Souza M, Herrerias T, Zaleski T, Forgati M, Kandalski PK, Machado C, Silva DT, Piechnik CA, Moura MO, Donatti L (2018) Heat stress in the heart and muscle of the Antarctic fishes Notothenia rossii and Notothenia coriiceps: Carbohydrate metabolism and antioxidant defence. Biochimie 146:43-55. doi 10.1016/j.biochi.2017.11.010

24. Thatje S, Hillenbrand C-D, Mackensen A, Larter R (2008) Life hung by a thread: Endurance of Antarctic fauna in glacial periods. Ecology 89:682-692. doi 10.1890/07-0498.1

25. Ukidve A, Zhao Z, Fehnel A, Krishnan V, Mitragotri S (2020) Erythrocyte-driven immunization via biomimicry of their natural antigen-presenting function. Proceedings of the National Academy of Sciences 117

26. Wang A, Chao T, Ji Z, Xuan R, Liu S, Guo M, Wang G, Wang J (2020) Transcriptome analysis reveals potential immune function-related regulatory genes/pathways of female Lubo goat submandibular glands at different developmental stages. PeerJ 8:e9947. doi 10.7717/peerj.9947

27. Wang B, Li F, Xiang J, Gui L, Luo Z, Yan H (2010) Three tetraspanins from Chinese shrimp, Fenneropenaeus chinensis, may play important roles in WSSV infection. J Fish Dis 33:15-29. doi 10.1111/j.1365-2761.2009.01079.x

28. Won WJ, Kearney JF (2002) CD9 is a unique marker for marginal zone B cells, B1 cells, and plasma cells in mice. J Immunol 168:5605-5611. doi 10.4049/jimmunol.168.11.5605

29. Wu F, Su P, Chen L, Li M, Liu X, Li Q (2012) Cloning of arctic lamprey Lethenteron camtschaticum cd9 with roles in the immune response. J Fish Biol 81:1147-1157. doi 10.1111/j.10958649.2012.03299.x

30. Xu Q, Cai C, Hu X, Liu Y, Guo Y, Hu P, Chen Z, Peng S, Zhang D, Jiang S, Wu Z, Chan J, Chen L (2015) Evolutionary suppression of erythropoiesis via the modulation of TGF-beta signalling in an Antarctic icefish. Mol Ecol 24:4664-4678. doi 10.1111/mec.13344

31. Yang S, Chen W, He F, Fu S, Jin Z, Zheng C, Zhang X, Ye Z, Jin H, Qian S, Sun Y, Huang M, Lv Z, Fei H (2020) Comparison of the roles of IgM in systemic and mucosal immunity via tissue distribution analysis in largemouth bass (Micropterus salmoides). Aquaculture 527 doi 10.1016/j.aquaculture.2020.735488

32. Yoon SO, Zhang X, Lee IY, Spencer N, Vo P, Choi YS (2013) CD9 is a novel marker for plasma cell precursors in human germinal centers. Biochem Biophys Res Commun 431:41-46. doi 
10.1016/j.bbrc.2012.12.102

33. Zhu J, Yan K, Lu L, Peng C, Zhou C, Chen S, Xie X, Dong M, Xu A (2006) Molecular cloning and characterization of CD9 cDNA from cartilaginous fish, red stingray, Dasyatis akajei. Mol Immunol 43:1534-1540. doi 10.1016/j.molimm.2005.10.005

34. Zhu LY, Lin AF, Shao T, Nie L, Dong WR, Xiang LX, Shao JZ (2014) B cells in teleost fish act as pivotal initiating APCs in priming adaptive immunity: an evolutionary perspective on the origin of the B-1 cell subset and B7 molecules. J Immunol 192:2699-2714. doi 10.4049/jimmunol.1301312

\section{Figures}

\section{A}

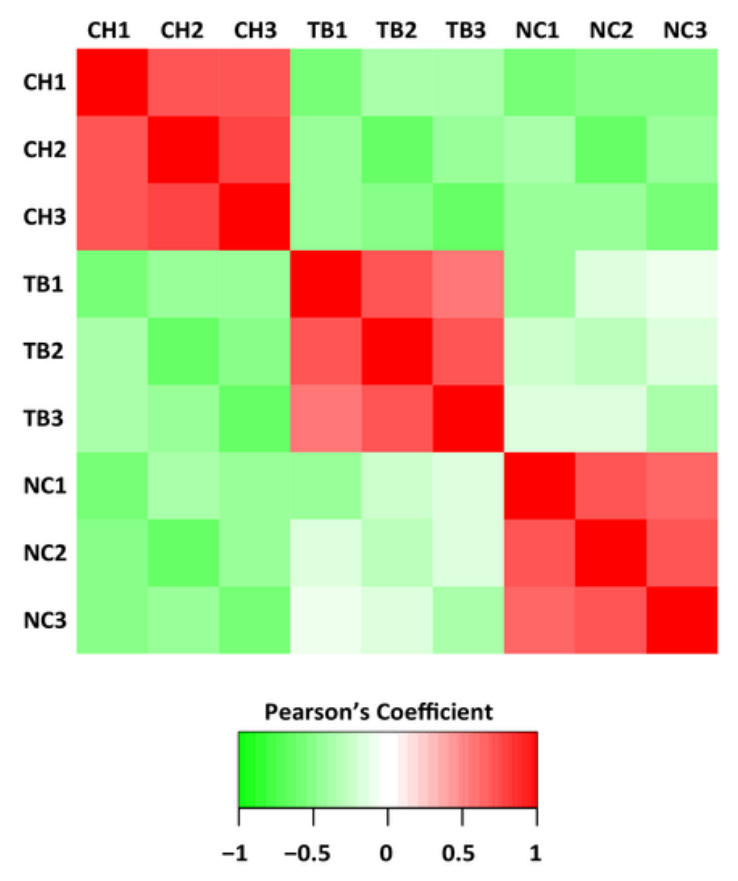

B

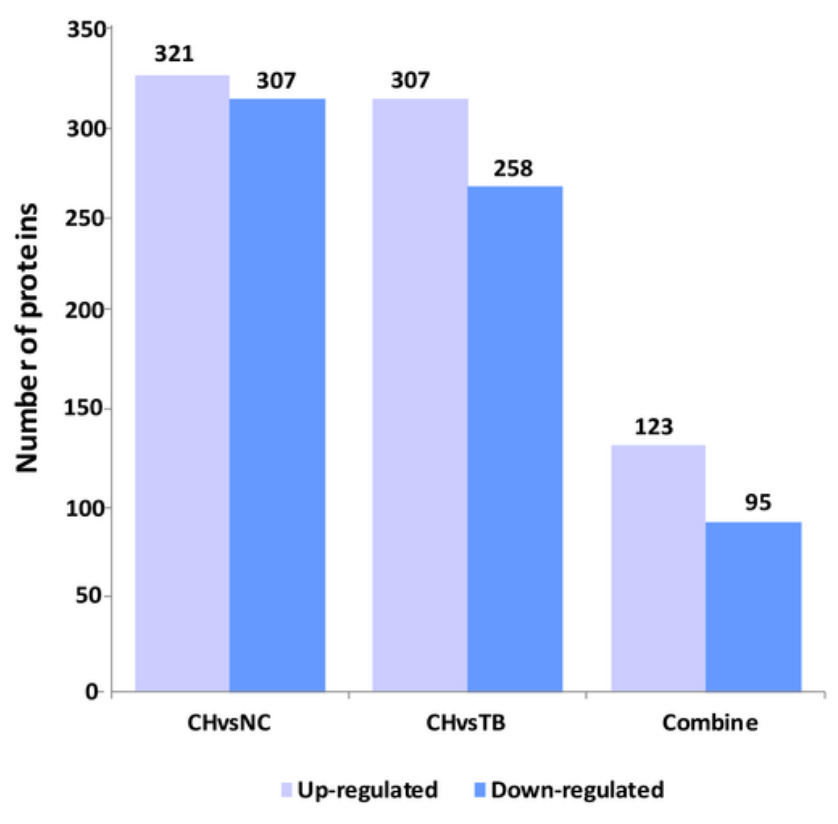

\section{Figure 1}

(A) Reproducibility analysis. (B) Summary of differentially quantified proteins. 

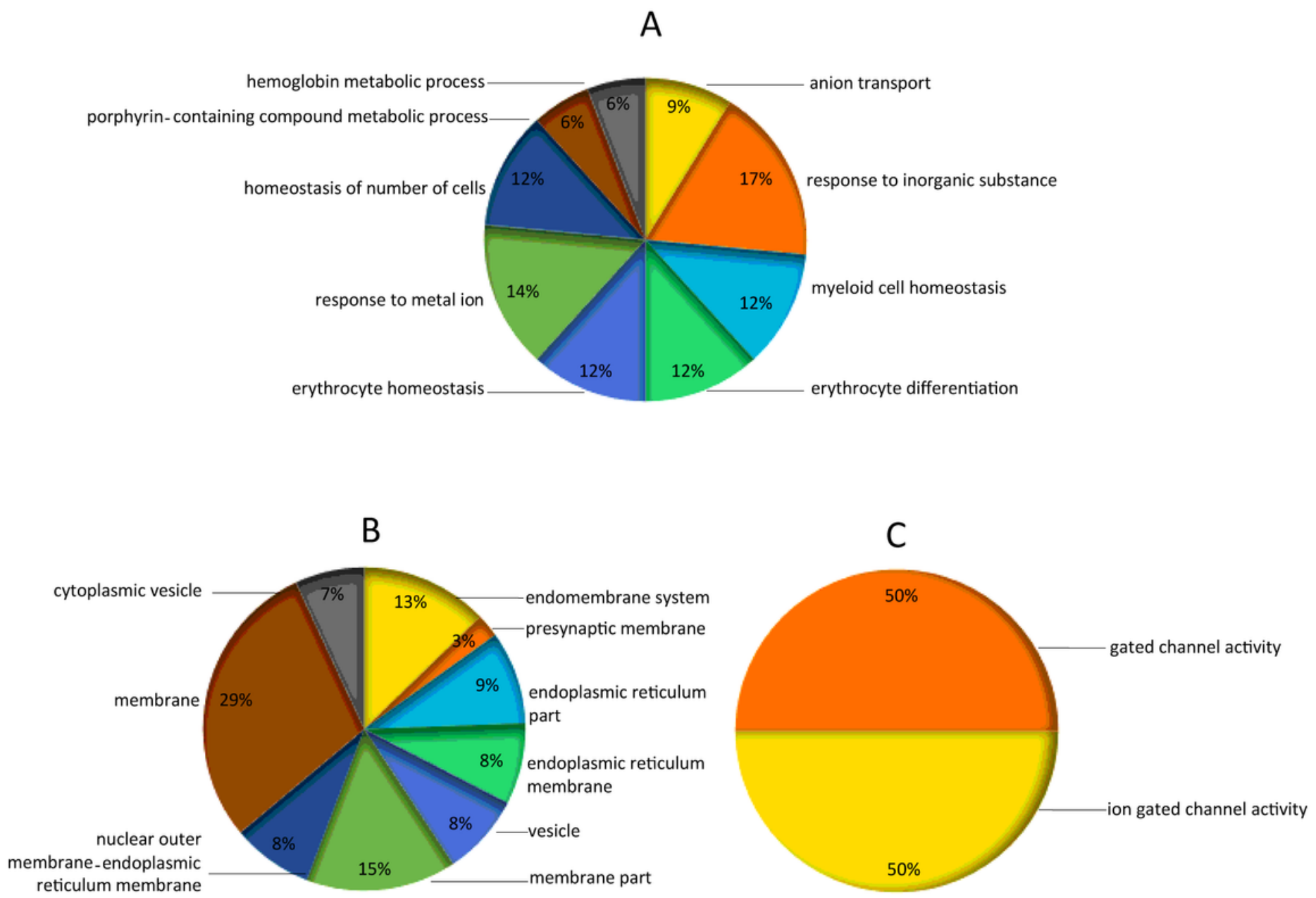

\section{Figure 2}

Functional classification of differentially quantified proteins ( $\mathrm{CH}$ vs combine). (A) Biological processes; (B) cellular components;(C) molecular functions. 
glycoprotein metabolic process

gated channel activity

divalent metal ion transport

endoplasmic reticulum membrane

endoplasmic reticulum membrane network

endomembrane system

membrane part

endoplasmic reticulum part

membrane glycoprotein metabolic process

Golgi membrane

endoplasmic reticulum

organelle membrane

Golgi apparatus part

cytoplasmic vesicle

gated channel activity

ion gated channel activity

ion channel activity

channel activity

passive transmembrane transporter activity

substrate-specific channel activity

\title{
$\begin{array}{lllllllll}0 & 0.5 & 1 & 1.5 & 2 & 2.5 & 3 & 3.5 & 4\end{array}$ -log10(Fisher' exact test $p$ value)
}

GO-based enrichment analysis of up-regulated proteins

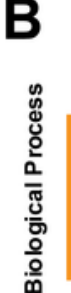

actin filament-based movement

muscle system process

muscle contraction

embryonic hemopoiesis

hemoglobin metabolic process

hemoglobin biosynthetic process

riated muscle contraction

cardiac muscle contraction

immune system process

positive regulation of multicellular organismal process

homeostatic process

homeostasis of number of cells

muscle thin filament tropomyosin

mitotic spindle

sarcoplasm

sarcoplasmic reticulum

nuclear inner membrane

main axon

peptide binding

amide binding

\author{
$\begin{array}{lllllllll}0 & 0.5 & 1 & 1.5 & 2 & 2.5 & 3 & 3.5 & 4\end{array}$ \\ $-\log 10$ (Fisher' exact test $p$ value)
}

GO-based enrichment analysis of down-regulated proteins

\section{Figure 3}

GO-based enrichment analysis of up-regulated proteins (A) and down-regulated proteins (B) (CH vs combine). 


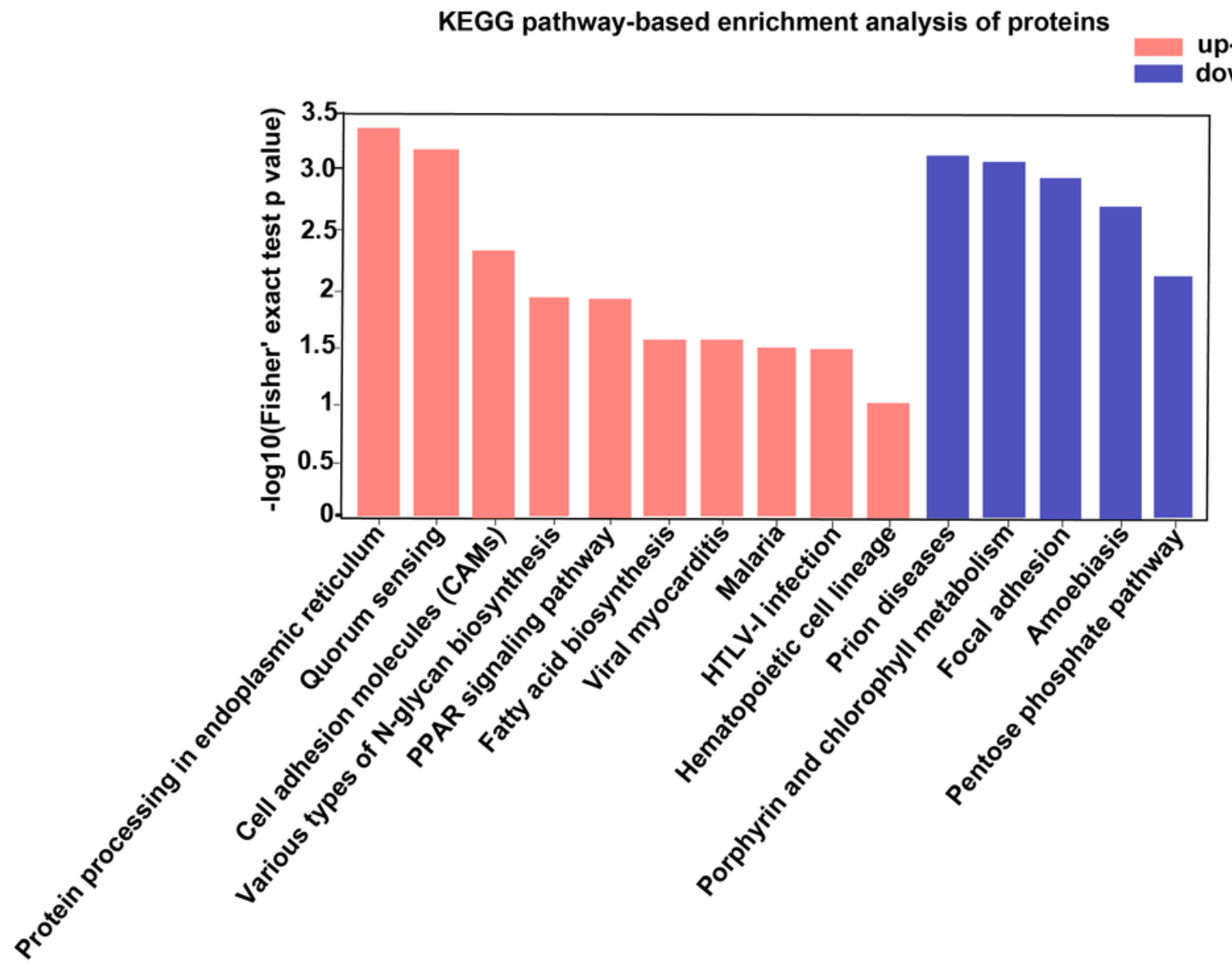

Figure 4

KEGG pathway-based enrichment analysis of up-regulated and down-regulated proteins ( $\mathrm{CH}$ vs combine). 


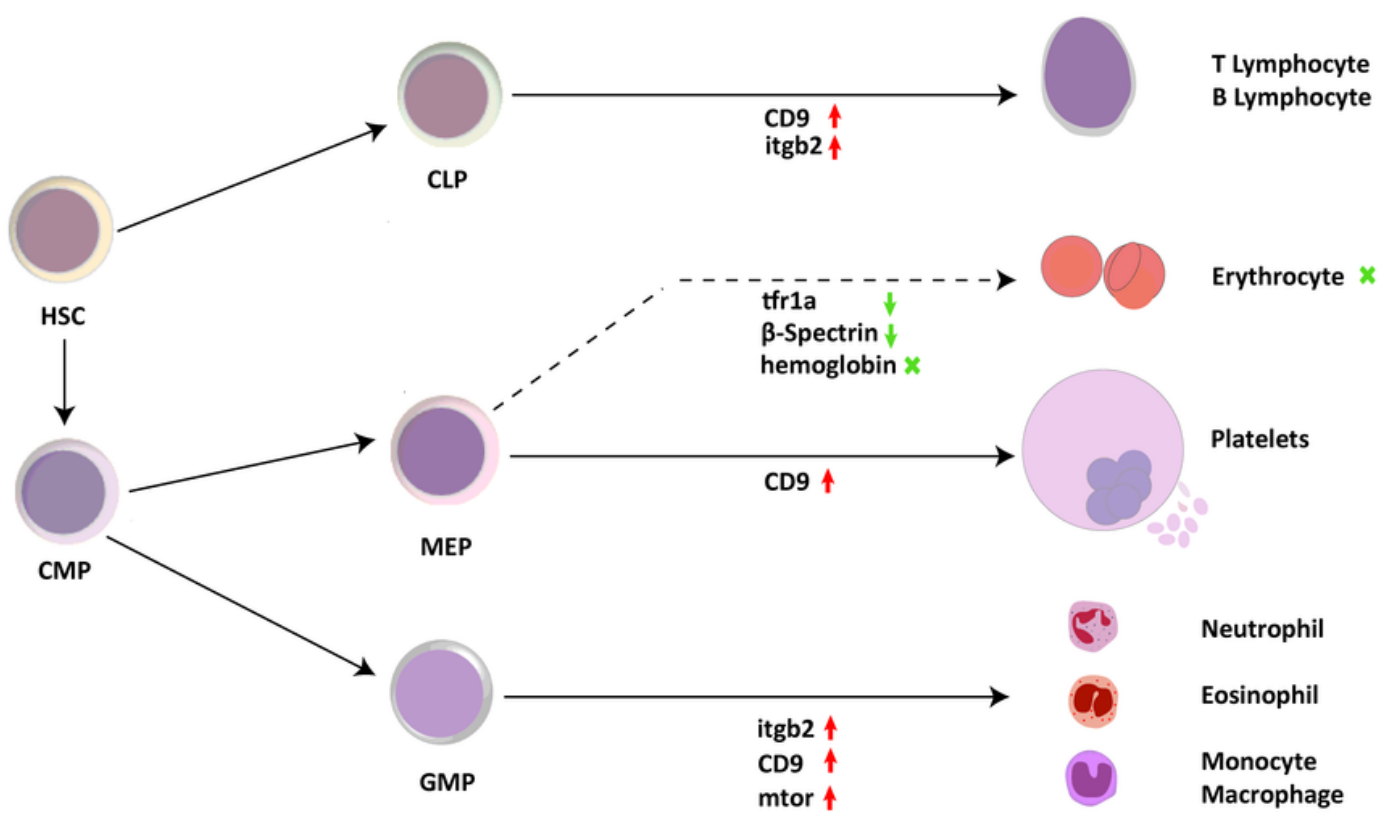

\section{Figure 5}

The red arrows indicate the upregulated proteins, in the icefish compared with the red-blooded fish (see Table 1, Supporting information). HSC: haematopoietic stem cell; CMP: common myeloid progenitor; CLP: common lymphoid progenitor; MEP: megakaryocyte/erythroid progenitor; GMP: granulocyte/macrophage progenitor.

\section{Supplementary Files}

This is a list of supplementary files associated with this preprint. Click to download.

- SupplementaryMaterialTable1.docx 